\title{
Database Framework for Nigerian Prison Service, Adamawa State, Command
}

\author{
Emeje Gideon Daniel ${ }^{1}$, Thomas Labiga Laban ${ }^{1}$, Shallmombol Gabriel Ldutsi ${ }^{2}$ \\ ${ }^{1}$ Department of Computer Science, Modibbo Adama University of Technology, Yola, Nigeria \\ ${ }^{2}$ Department of Information Technology, Modibbo Adama University of Technology, Yola, Nigeria
}

Email address:

emejegid@gmail.com (E. G. Daniel), labiga65@gmail (T. L. Laban)

To cite this article:

Emeje Gideon Daniel, Thomas Labiga Laban, Shallmombol Gabriel Ldutsi. Database Framework for Nigerian Prison Service, Adamawa State, Command. American Journal of Computer Science and Technology. Vol. 3, No. 3, 2020, pp. 38-45. doi: 10.11648/j.ajcst.20200303.11

Received: January 14, 2020; Accepted: February 3, 2020; Published: June 9, 2020

\begin{abstract}
One of the major challenges facing prisons service especially in the developing countries like Nigeria is how to accurately and efficiently analyze the growing volume of prison inmate data. Nigerian Paramilitaries particularly the Nigerian Prison Service (NPS) Adamawa State command keep volumes of inmate data and information. Despite the enormously volume of data which is on the increase, the recordkeeping process remains manual; this does not assure proper safe keeping of inmate records. This study designed a database framework for the NPS Adamawa State command. The study analyzed the existing system of recordkeeping adopted by NPS which is the manual method of record keeping; developed a prototype database model; and designed a web application that would interact with the database. Before the main design, a comprehensive analysis of the existing system was carried out. 16 staff were interviewed for the exercise and the result showed the need for Nigerian Prison Service (NPS) Adamawa State command to have such robust database framework for accurate and efficient tracking of inmate data. The system was designed using Microsoft SQL server, MS Visual Studio. The researcher also used agile software development methodology and accomplished the development by the use of C-sharp, JavaScript, HTML 5 and Bootstrap CSS as tools. The system was tested using a workable prototype, and major recommendations were made. The researcher believes such a database framework should be deployed to Nigerian Prison Service (NPS) Adamawa State Command for full implementation. Findings of this work suggest that similar paramilitaries like the Nigerian Prison Services (NPS) should also incorporate a centralized database system into their process. Though further research needs to be conducted regarding the introduction of bio-metric fingerprinting as a means of tracking prison inmates in such organizations; this work is of the opinion that data warehousing of all prison data for the Nigerian Prison Service (NPS) as a whole is a necessary/vital way forward.
\end{abstract}

Keywords: Database Framework, Relational Model, Normalization

\section{Background of the Study}

As the technology evolution is taking place, there arose a need for centralization of prisoners' record to facilitate information exchange and data sharing among prisons' authorities. This reduces administrative overheads, speed up responsiveness to users, reduce risks involved in inmates' custody, eliminated obsolete processes and reap cost- cutting benefits.

A prison is a place used to confine people that are convicted or awaiting trial. It includes the land, the house and every other structure located within the institution used for the purpose of detention. This led to the establishment of the first prison administration modeled on British tradition, and staffed by officers trained in the same tradition when the then Governor, H. S. Freeman, in 1862, was commissioned, interalia, to appoint judges and other officers. Hence, the Broad Street Prison was built in Lagos in 1872, but the prison ordinance providing for the establishment of prison was passed along with the Supreme Court ordinance in 1876. Therefore, the prisons administration in Nigerian started in 1876, when the prison ordinance came into force. But, from 1876 to 1920 , the police department ran it. However, by 1920, the police ceased to be in-charge of prisons administration in Nigeria [1]. The Nigerian Prison Service, Yola Provincial Prison was established in the year 1914. 
Computer today is an important tools used in compiling manual data to an automated records. Computer system enables storage and retrieval of information quickly, sorting, querying and reduced work complexity. The increase in the speed of work has helped organizations to do many things with fewer resources. A Prison, penitentiary, or correctional facility is a place in which individuals are physically confined and usually deprived of a range of personal freedom [2].

The prisons' major challenge in developing countries like Nigeria is how to accurately and efficiently analyze the growing volume of prisons inmate data [3]. As the volume of this inmate data becomes very large, new techniques of managing data is required to turn the data into useful information. Database makes it easy, convenient, and practical to explore very large amount of inmate records with the Nigerian Prisons Service.

Due to prison congestion in Nigeria, criminal and other armed individuals often brake jail or prison facilities resulting to loss of inmates' record. Nigerian prisons lacks the framework that will effectively and accurately handle the growing inmates' population as their records are not centralized. Yola prison command manages its large volume of data manually, the storage file or books are subject to constant damages by termites, destructive insects, rodents and natural hazard like weather (wet season). This research designed a database framework for Jimeta and Yola Nigerian Prisons Service records so as to have quick access to data and enable the management have a well informed decision. This research is meant to upgrade the record keeping in the Nigerian Prison Service from the ancient manual record keeping to a modern automated system. The study analyzed the existing system of recordkeeping adopted by NPS which is the manual method of record keeping. A comprehensive analysis of the existing system was carried out where 16 staff were interviewed for the exercise and the result showed the need for Nigerian Prison Service (NPS) Adamawa State command to have such robust database framework for accurate and efficient tracking of inmate data.

\section{Literature Review}

With the technology evolution taking place, there is need for centralization of prisoners' record to facilitate data sharing among managers of the prisons. This reduces administrative overheads, speed up responsiveness to users, reduce risks involved in inmates' custody, eliminated obsolete processes and to have automated release diary generator.

Database Management System (DBMS) is an organized set of facilities for accessing and maintaining one or more database or series of database and through which all interactions take place with the database [4].

It is difficult to envisage how Nigerian Prison Service (NPS) operate efficiently and accurately without a centralize database, the analysis of the growing rate of inmate data is enormously increasing and new techniques have to be used.
Designing database framework for storing those data holds the promise of making it easy, convenient, and practical to explore very large amount of inmate records with the Nigerian Prisons Service [3].

Database Management is one of the most important tasks for an organization today. A system was proposed to integrate criminal databases from different state police databases to form a data warehouse for easy access and analysis of criminal data for necessary actions [5]. Other researchers designed a database security framework by combining different security mechanism on a sensitive student's information database application designed with the aim of minimizing and preventing the data from Confidentiality, Integrity and Availability threats [6]. These technologies allow data to be collected, stored and disseminated electronically though a working framework for Automatic Tuning of DBMS by using the Basic Utilities of Operating System was designed [7].

\subsection{Related Studies on Nigerian Prison Service (NPS) Technology}

In recent years, research has been carried out into the Nigerian Prison Service (NPS). The increasing growing need for Data integration, Data warehouse and Data mining as ways to improve the operations of principal actors within the prisons sector of Nigeria necessitate the development of an Automated Prison Information System for Nigerian Prison Service $[8,2]$. Automating the prison system will provide an easier way of computing prisoners' information, reliable storage of data, easy access and retrieval of information to authorized users' and also to provide high security for prisoners' record [9].

In order to facilitate management of all prisoners' records, an internet based prison management system was designed [10] while other researchers designed a system to handle both prisoners and visitors' record [11]. Management of prisons in Nigeria has long been a neglected area as it uses rudimentary process of storing prisoners' data in manual files and registers [12]. To that effect, a centralized management information system for Kisoro prison was developed [13].

\subsection{Major Properties of Databases}

A database is a collection of information that is organized so that it can be easily accessed, managed and updated [14]. The important properties of database system, that are essential for developing any secure and effective systems, are as follows [15].

i. Data integrity

ii. Data persistence

iii. Data security

iv. Data querying

\subsection{Challenges in Database Technology}

In recent years, several database approaches have been introduced and used to develop powerful and appropriate file storing systems. In fact, each approach provides several 
advantages and also disadvantages depending on the development environment as well as applications which it is integrated with. The systems are based on the principle of supporting versioning of development artefact as well as extending in data and transaction models to extend the functionality of the system [16].

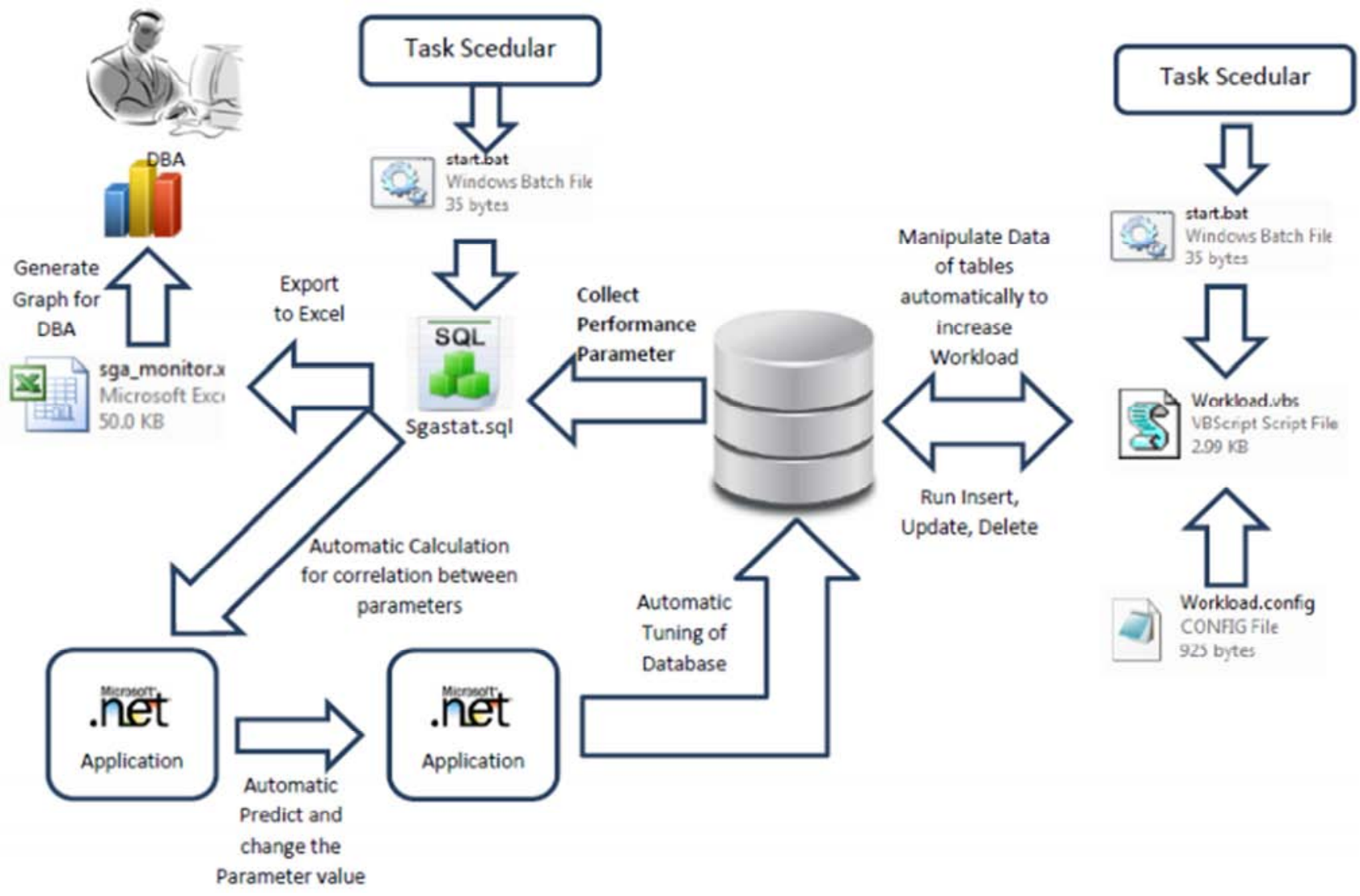

Figure 1. Automated Database Tuning Framework.

\subsection{Database Models}

In database systems, a data model is used to explicitly specify the data structure of a database in which each data element associates one another as well as providing the definition, format, and relationship among the data to realize the aims of a business. A model is a realization of a formalization and documentation of existing or ideal events and processes interpreted during the system design phase to visualize and translate complex system specifications and technical requirements into a precise and understandable representation of event and process flows. The representation is generally generated as formal diagrams or flowcharts to illustrate the relationship between data elements and also ensures all of the specifications and requirements have been identified and structured [17].

\subsection{Relational Model}

A relational model is based on a collective set of multiple data sets represented in a tabular form consists of general model components [18] i.e. tables, records and columns to establish a concrete defined relationship among database tables and components. Relationships of components to establish communication between tables and also allows every component to share information between each other that facilitates data search ability, organization and reporting when performing system analysis using mathematical techniques [19]. Each relationship defines a specific manner of the linkages among tables in database that provides different advantages and functionalities in database organization, these are:

One-to-one, One-to-many, Many-to-one and Many-tomany

\subsection{Database Normalization}

Normalization is a set of rules by which tables or entities in the relational model are designed to be connected through relationships using Primary Keys and Foreign Keys in order to overcome the problem of complex domains [20]. Normalization refers to the process of dividing tables into sub tables as a part of making database management operations easy and simple. The benefits of normalization are as follows: Avoid anomalies from updating, Optimize queries, Provide data integrity and Increase speed and flexibility of queries, sorts and summaries.

E. F. Codd introduced three types of normalization process which are termed as First Normal Form (1NF), Second Normal Form (2NF) and Third Normal Form (3NF). From 
more extended research on normalization process, two other normal forms are specified which are known as Fourth Normal Form (4NF) and Fifth Normal Form (5NF) [21]. The first three form of normalization are described as:
i. First Normal Form (1NF)
ii. Second Normal Form (2NF)
iii. Third Normal Form (3NF)

\subsection{Data Query Language}

Relational databases use a well-structured language to get access to the database and subsequently retrieve the information which is popularly known as Structured Query Language (SQL). During the 1970s, a data manipulation language called Structured English Query Language (SEQL) for getting access to integrated relational databases. Later SEQL was changed to SQL as it was already patented by another company. SQL gained popularity within a very short period of time and major RDBMS vendors integrated SQL with their systems. The prime reason behind the increased popularity was development facility. SQL reduces developers' involvement for their coding as they do not need to write additional code for data query which ultimately reduces the development cost. Considering the popularity and wide spread implementation of SQL, the American National Standards Institute (ANSI) developed a standard for SQL which is known as ANSI SQL. Based on the industry standard ANSI SQL there are different forms of SQL used by different relational database vendors [21].

\subsection{Non-relational Database}

To database administrators and many others familiar with the traditional relational model of database structure, the non- relational may not seem like a database at all. One of the most ubiquitous applications of this paradigm is Google's massive archive of the internet which reportedly takes up petabytes of space [22]. According to Stonebraker, "all the major Web-search engines use home-brew text software to serve us search results. None use relational DBMSs" [23].

\subsection{Database Management Systems}

Database Management System (DBMS) is an organized set of facilities for accessing and maintaining one or more database or series of database and through which all interactions take place with the database. The interactions catered for by most existing DBMS fall into four (4) main groups [4].

i. Data definition: defining new data structures for a database, removing data structures from the database, modifying the structure of existing data.

ii. Data maintenance: inserting new data into an existing database structures, updating data in existing data structures, deleting data from existing structure.

iii. Data retrieval: querying existing data by end users and extracting data for use by application programs.

iv. Data control: creating and monitoring users of the database, restricting access to data in the database and monitoring the performance of database.

\section{Methodology}

The Database was designed using Relational Database Model Design, Microsoft SQL Server for the framework to receive input data from the users or the system administrators of the proposed system.

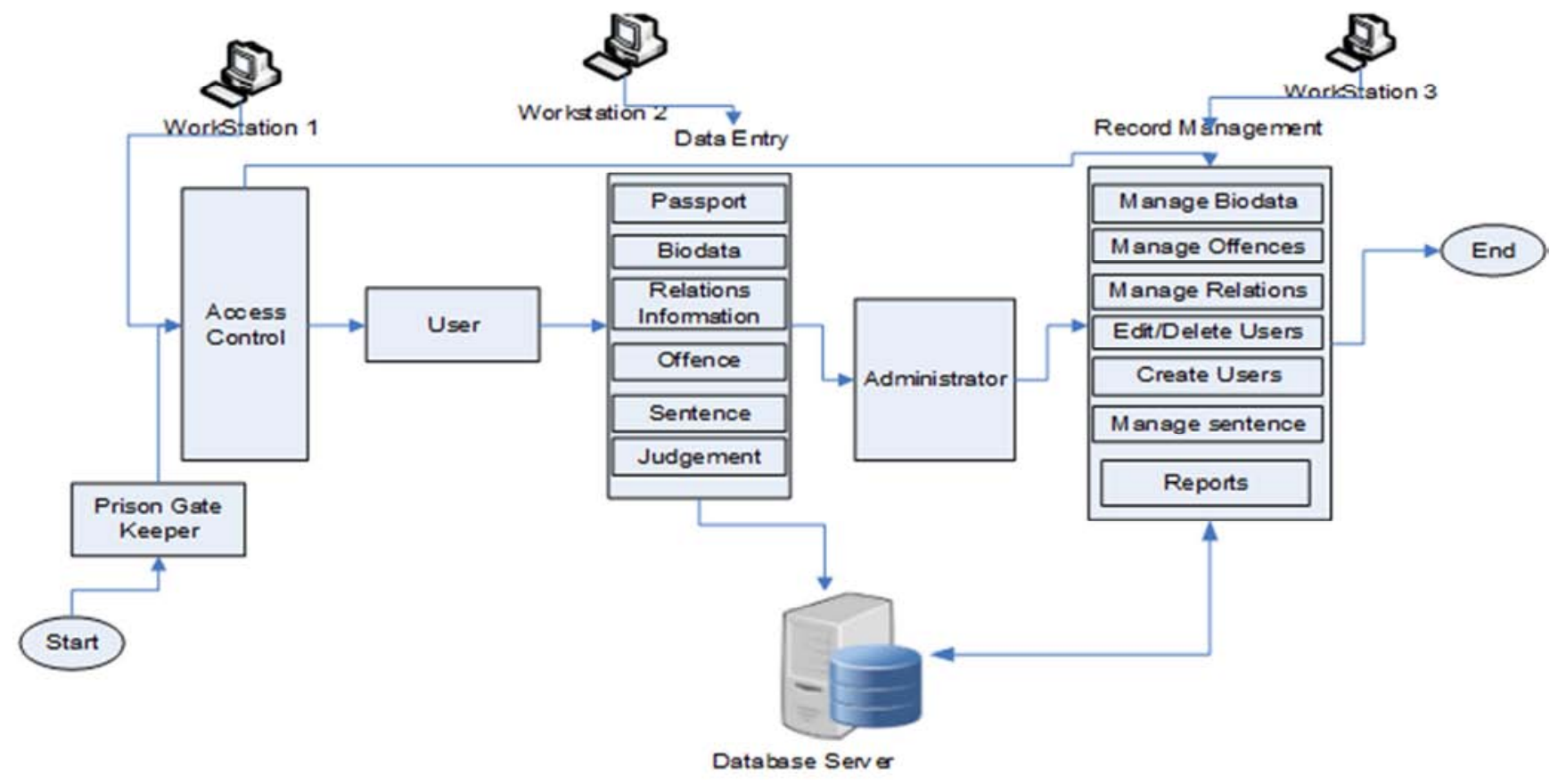

Figure 2. Proposed System Architecture. 


\section{Research Results}

This chapter has described the actual implementation processes for designing the Database framework for Nigeria Prison Service, Yola Area Command.

\subsection{Data Presentation}

The data was collected by interviewing the prison officials from Yola-South and Yola-North prison in Adamawa State.

\subsection{Database Structure and Design}

From the designed logical Data models, the researcher has designed the actual physical Data Models of all the independent and dependent Data Models for the Nigerian Prison Service database on an SQL Server Database
Management Studio 2012. The actual database design and the table schema.

\subsection{User Interface}

\section{Login Page}

The system input was designed so as to receive data from the users and administrators of the Database system.

The first set of input to the system is the Login Page (a pair of Username and Password). After the pair has been entered, the system authenticates either the user or the administrator by validating the username and password. This is done by calling the login procedure which in turn checks the database by verifying if both the Username and Password supplied exist in the database. If true, the system authenticates.

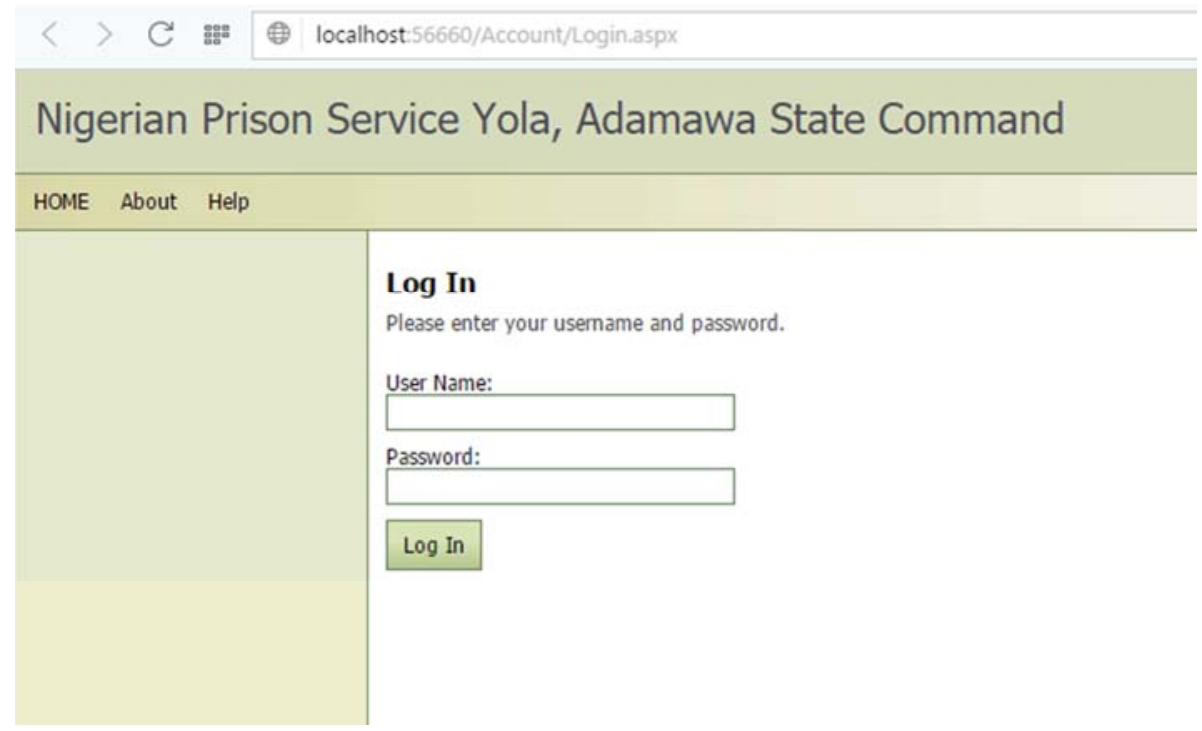

Figure 31. A Snapshot of Login Page.

The Home Page

This is the first page one comes across immediately after gaining access to the system, the page menu items will be assign based on the level of access privilege each person is granted on the system as either Administrator or User.

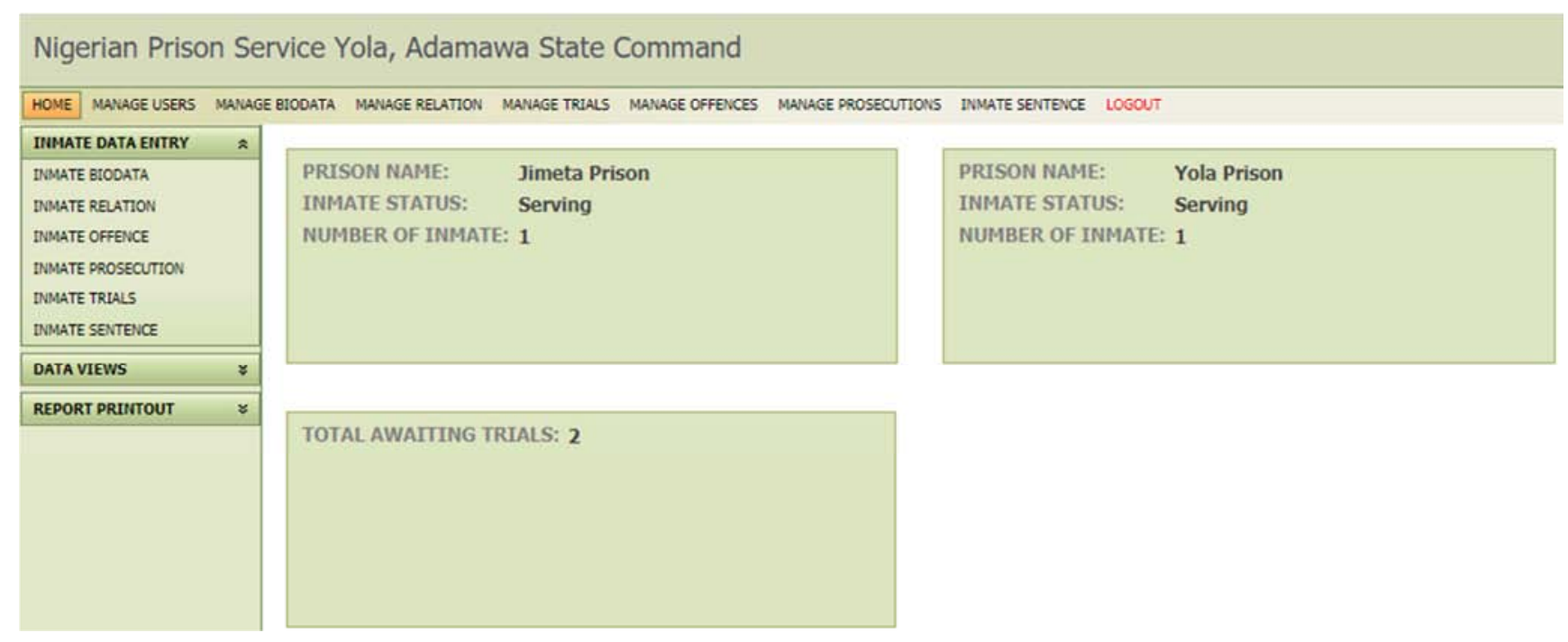

Figure 42. Administrators Menu Display. 
New Inmate Biodata Registration

The new Inmate Biodata Registration page is used by the system users for capturing new inmates into the system, they do this by filling up the form fields made available through a web browser. A form called New Inmate Relations Registration form is used for capturing inmates' relations information to be saved into the database for emergency purposes. Other forms are Inmate Offence Registration Form", "Inmate Prosecution Registration Form", "New Inmate Sentenced Form", "Inmate Trials Registration Form" and "New Inmate Sentenced Form".

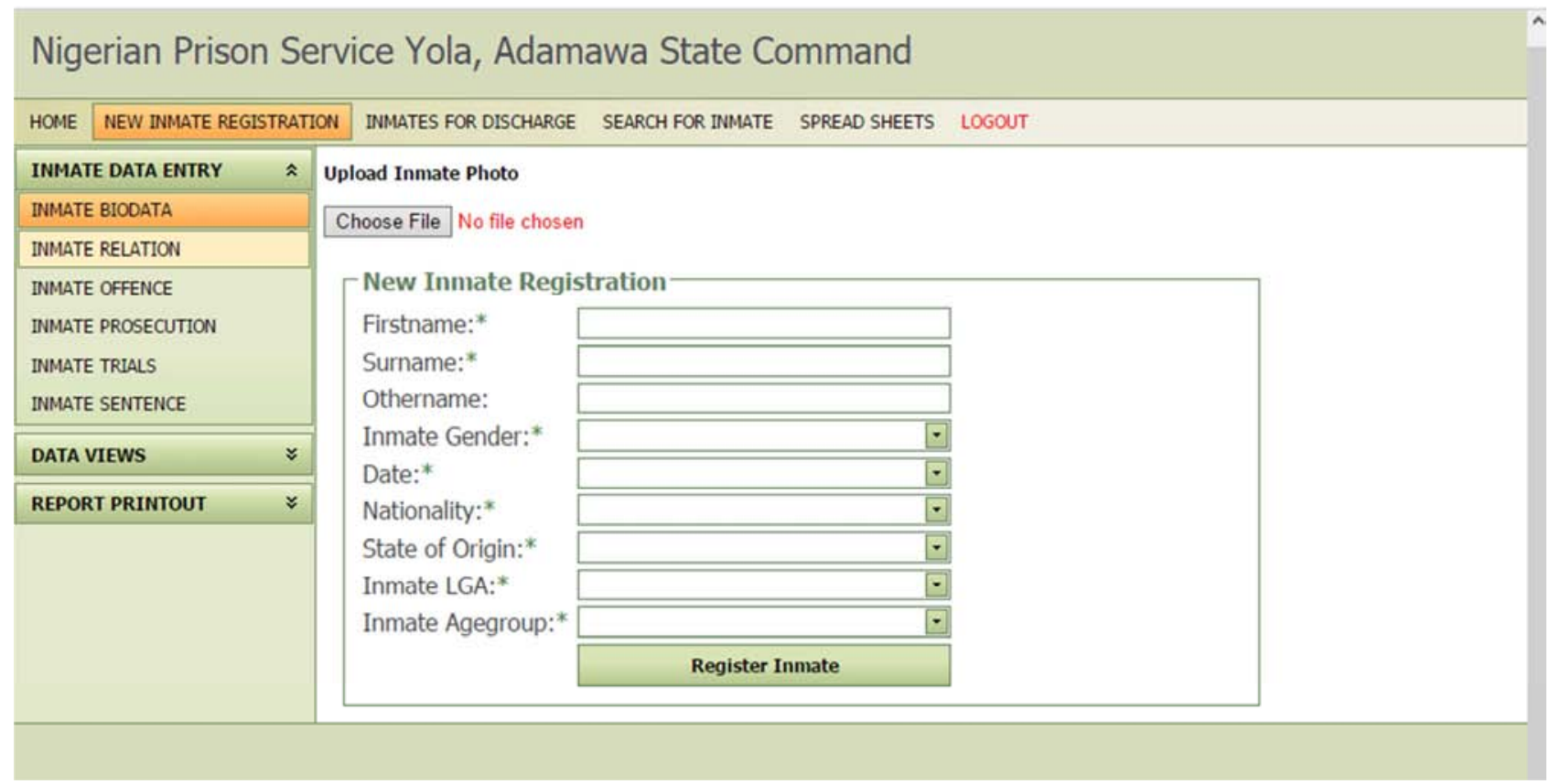

Figure 5. New Inmate Registration Form.

View of Inmates Awaiting Trials

The Inmate awaiting trial view page is basically used by users to view all information regarding all the inmates awaiting trials, the page allows the users to be able to view Inmate ID, the inmate trials date and time, the attached officers name and some details regarding the trials of each inmate. The users would only view that information but cannot be able to edit or delete any information on the page because users do not have the privilege to delete or update records.

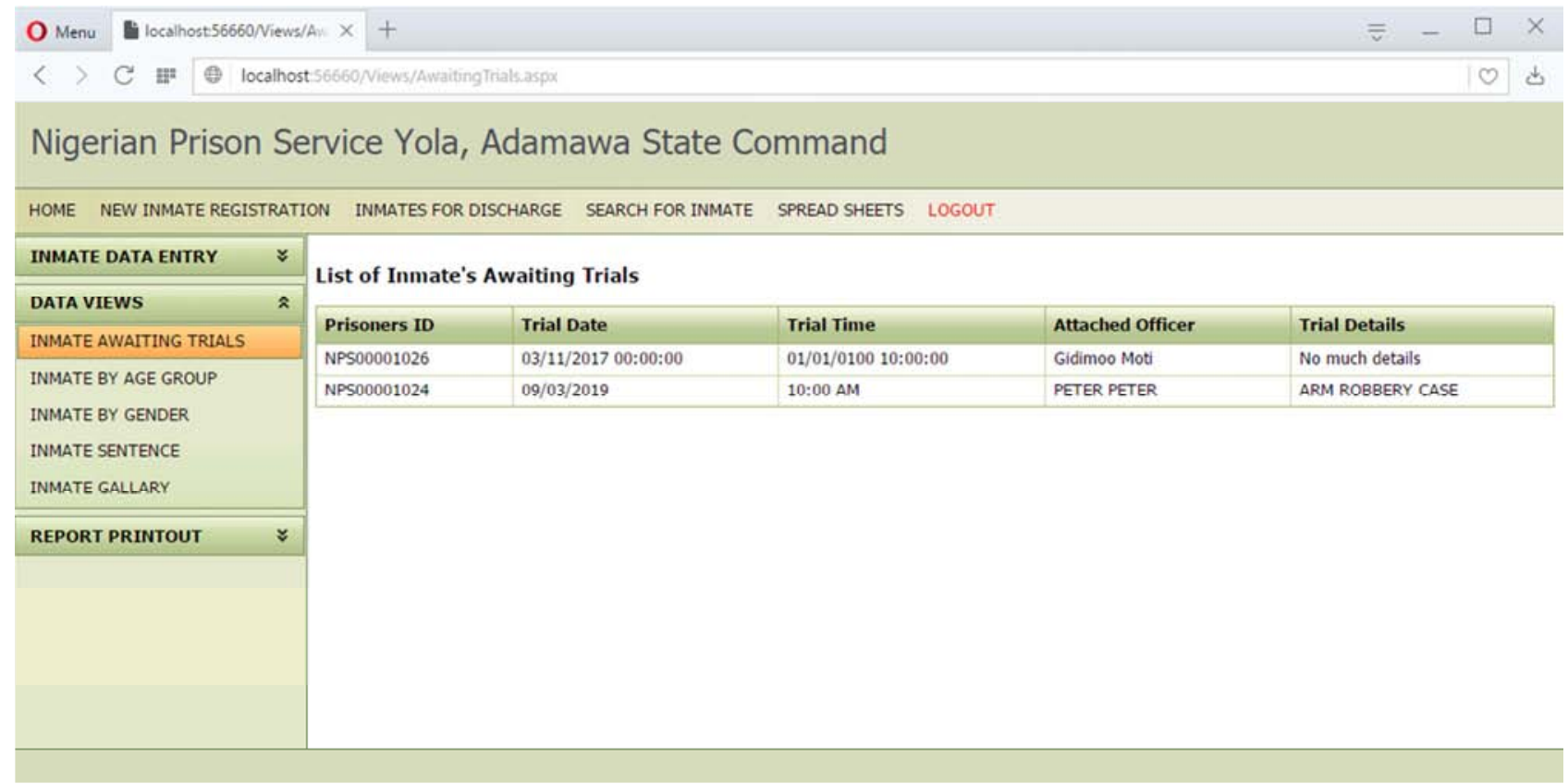

Figure 6. View of Inmates Awaiting Trials. 
View of all Sentenced Inmates

The Sentenced Inmate view is similar to the inmate awaiting trials view but in this case the sentenced inmate view is displaying information regarding the entire inmates' that are sentenced. The view display information like the inmate ID, the duration of the sentenced, the entry and discharge date and time of the inmate, the cell number information in which the inmate is and finally the status of the inmate, is he released or still serving his sentenced. See Figure 7.

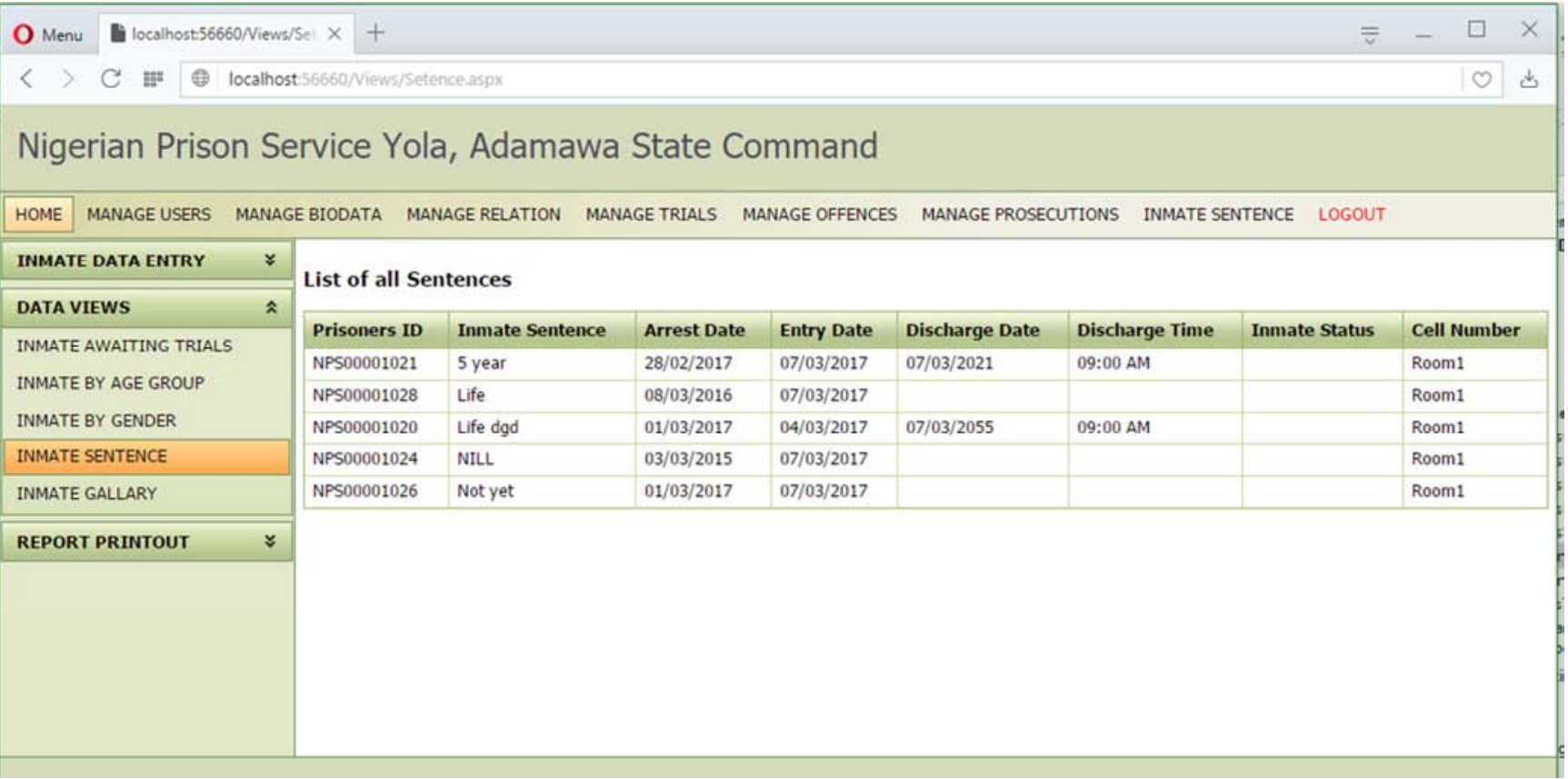

Figure 7. View of all Sentenced Inmates.

Inmates Biodata Printout

The inmate Biodata printout is where printouts of inmate basic information are displayed to be printed through a printer, this page is available for both the users and the administrators of the system. The print out are made in such a way that, they could be exported in different format in case where there are no printers available. See Figure.

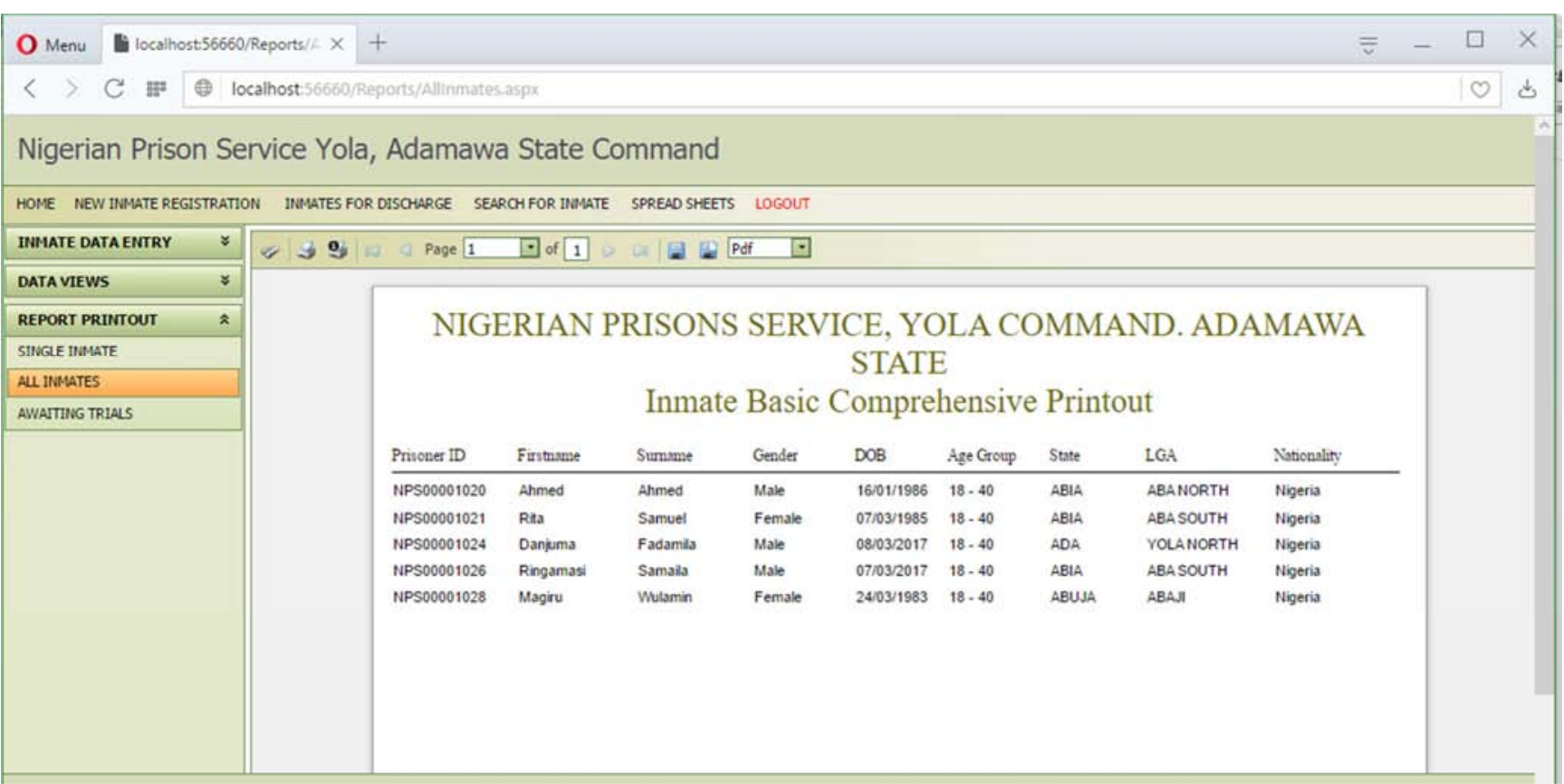

Figure 8. Printout of All Inmates Biodata. 


\section{Conclusion}

The design if fully implemented will offer a secured and robust means of keeping inmate records, to the current traditional method of inmates' recordkeeping adopted by the Nigeria Prison Service, Yola Command. The design will eliminate the current inability of the prisons service to take proper analysis of inmates' conditions and for decision makers not being able to take concrete decisions in respect to the inmates. The system is design to handle various activities ranging from the process of inmate registration, inmates record retrieval for reporting, viewing and record management.

\section{References}

[1] Onyekachi J (2016). Problems and Prospects of Administration of Nigerian Prison: Need for Proper Rehabilitation of the Inmates in Nigeria Prisons. J Tourism Hospit 5: 228. doi: 10.4172/2167-0269.1000228.

[2] Oye, N. D. and Ibrahim Inuwa. (2015). Prison Inmate Information System: The Case of Yola Central Prison, Nigeria. West African Journal of Industrial and Academic Research April 2015 Vol. 13 No. 1.

[3] Chen, H., Chung, W., Xu, J. J., Wang, G., Qin, Y., and Chau, M. (2004). Crime Data Mining: A General Framework and Some Examples. Computer, 37 (4), 50-56.

[4] Paul, B. (2013). Database Management System 3rd Edition. Published by Palgrave Houndmills, Basingstoke, Hampshire, RG216XS. New York.

[5] Obunadike G. N. and R. K. (2013) “A Frame Work For Data Warehouse For Nigerian Police Force" Department of Mathematical Sciences and IT, Federal University, Dutsin-ma, Katsina State, Nigeria.

[6] Sani H. M. and Yabo M. M. (2015), A Database System Security Framework. International Journal of Computer Science \& Information Technology (IJCSIT) Vol 7, No 6 . DOI: $10.5121 /$ ijcsit.2015.7614.

[7] Hitest. K. S., Shastri A. and Ranjit B. (2012) "AFramework for Automated Database Tuning using Dynamic SGA Parameters and Basic Operating System Utilities". Database Systems Journal", Academy of Economic Studies-Bucharest, Romania.

[8] Obunadike G. N. and Ume A. (2014) "Leveraging Data Mining and Data Warehouse to Improve Prison Services and Operations in Nigeria" Department of Mathematical Sciences and IT, Federal University, Dutsin-ma, Katsina State, Nigeria.

[9] Royce, W. (1970), "Managing the Development of Large Software Systems", Proceedings of IEEE WESCON.

[10] Amol G. C., Prashant V. B., Swapnil N. C. and Priyanka V. G. (2010), Prison Management System. J. T. Mahajan College of
Engineering, Faizpur. Maharashtra. Retrieved from https://www.ibm.com/developerworks/community/files/basic/ anonymous/api/library/94bf907e-ea 05- 439a-be58c1252ca742ae/document/0f84d12d-35bd-4681-8b79fe $42 \mathrm{e} 1 \mathrm{e} 2638 \mathrm{a} /$ media on $12 / 01 / 2020$.

[11] Murugan, R. (2008). Prison File Monitoring System. International Journal of Recent Engineering Research and Development (IJRERD), 1 (5), 5-8.

[12] Akpojaro, J. and Omogbhemhe, M. I. (2017), A Conceptual Design of Information System for Prison Management in Nigeria. Asian Journal of Mathematics and Computer Research 15 (2): 131-140, 2017 ISSN: 2395-4205 (P), ISSN: 2395-4213 (O).

[13] Ahishakiyea, E., Taremwab, D. and Elisha O. O. (2017). A Secure Web Based Records Management System for Prisons: A Case of Kisoro Prison in Uganda International Journal of Computer (IJC) ISSN 2307-4523 (Print \& Online) http://ijcjournal.org/.

[14] Dittrich, K. (2000). "Databases in Software Engineering: A Roadmap," Department of Information Technology, University of Zurich, Winterthurerstr. 190 CH-8057 Zurich, Switzerland.

[15] Ebel, F., et al. (2008). "Festo Learning Systems: Automation Technology", Festo Corporation, United States of America, 2008.

[16] Parawee, P. (2015). Database centric software test management framework for test metrics. Faculty of Computer Science, Department of Computer Engineering Technische University ät Chemnitz, June 2015.

[17] Ballard, C. (1998). "Data Modeling Techniques for Data Warehousing," IBM Corporation, International Technical Support Organization, California, February 1998.

[18] Stajano, F. (1998). "A Gentle Introduction to Relational and Object Oriented Databases," ORL Technical Report TR-98-2, Cambridge, United Kingdom, 1998.

[19] Tatamcgraw-Hill (2006) "Introduction to database management systems," Tata McGraw-Hill Publishing Company Limited, Delhi, 2006, ISBN: 0-07-059119-9.

[20] Ferreira C. \& Cohen J. (2008), Agile systems development and stakeholder satisfaction: a South African empirical study, retrieved https://dl.acm.org/doi/10.1145/1456659.1456666.

[21] Alam, F. (2015). Data Migration: Relational Rdbms To NonRelational Nosql. M. Sc. Thesis, Ryerson University, Toronto, Ontario, Canada.

[22] Harrington, J. (2009). Relational Database Design and Implementation: Clearly Explained. Burlington: Morgan Kaufmann Publishers, 2009.

[23] Kavanagh, D. "Relating to Amazon SimpleDB." March 4, 2008. Web. 28 April 2011. $<$ http://aws.amazon.com/articles/Amazon-SimpleDB/1292>. 